\title{
An Unusual Cause of Dysphagia in a Mentally Retarded, Deaf and Dumb Child
}

\author{
S Basu, P Chandra, S Basu
}

\section{Citation}

S Basu, P Chandra, S Basu. An Unusual Cause of Dysphagia in a Mentally Retarded, Deaf and Dumb Child. The Internet Journal of Surgery. 2005 Volume 8 Number 2.

\section{DOI: $\underline{10.5580 / 1 \mathrm{f} 78}$}

\begin{abstract}
We report a 7 year old mentally retarded, deaf and dumb male child presenting with history of fever, cough and swallowing difficulty for 3 days. On examination he was found to be febrile with pharyngeal congestion and mild bilateral tonsilar enlargement. A provisional diagnosis of retropharygeal abscess was made, and an X-ray soft tissue neck was asked for. Surprisingly the X-ray showed a toe ring in the hypopharynx which was removed by esophagoscopy. It is extremely difficult to diagnose foreign body as the cause of dysphagia in a deaf and dumb child, especially in a mentally retarded one. This causes delay in diagnosis and increases complications. Physicians should maintain a high index of suspicion of such a rare cause of dysphagia in the mentally challenged children.
\end{abstract}

\section{INTRODUCTION}

Ingestion of foreign bodies is a common pediatric problem, with more than 100,000 cases occurring each year $\left.{ }_{1}\right]$. It is a well known pediatric emergency often requiring urgent esophagoscopy. The vast majority of such ingestions are accidental. The majority of foreign bodies pass out spontaneously, but serious complications though rare, such as bowel perforation and obstruction, can occur. As many patients who have swallowed foreign bodies are asymptomatic, physicians must maintain a high index of suspicion. We report an atypical presentation of dysphagia in a mentally retarded, deaf and dumb child which was due to foreign body ingestion.

\section{CASE REPORT}

A deaf and dumb male child of 7 years presented in Pediatric Emergency Room with history of fever, cough, difficulty in swallowing food and fluids and drooling of saliva for last 5 days (Fig. 1).

\section{Figure 1}

Figure 1: The child at the time of presentation

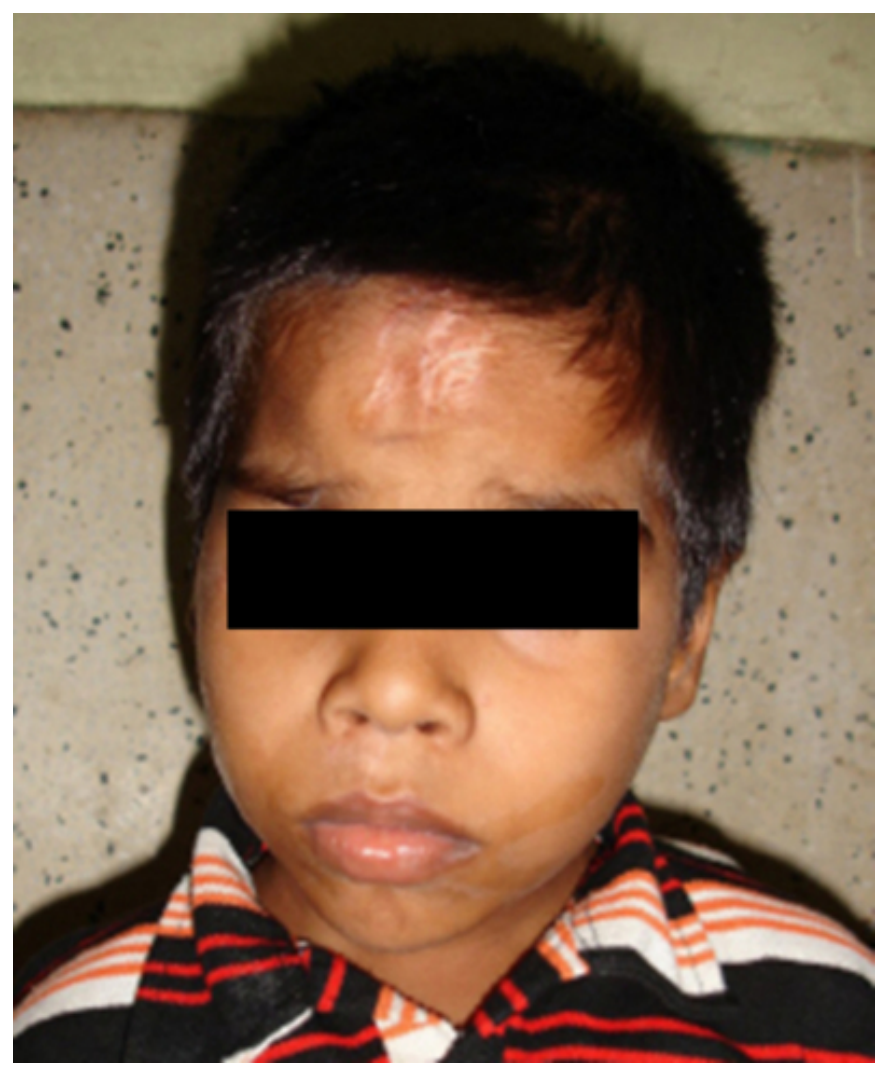

There was no stridor, cyanosis or respiratory distress. Before coming to the hospital, the child had been examined by two 
general practitioners and was diagnosed to be suffering from diphtheria and acute epiglottitis respectively. He received treatment without any prompt benefit. The parents informed that the child was mentally challenged since birth, and feeding difficulty and drooling of saliva had been present since infancy. They belonged to low socioeconomic bracket and the boy had never been immunized. On examination, he was found to be an apparently asymptomatic deaf and dumb child with mild mental retardation. Apart from fever (100.2 ${ }^{\circ} \mathrm{F}$ ), other vital parameters were normal. Pharynx was congested with bilateral mild tonsillar enlargement. No diphtheritic patch was seen and gag reflex was strongly elicited. On offering, the child took water in his mouth, did not swallow but ejected it out after about 1 minute. There was no nasal regurgitation. Other systemic examinations were unremarkable. The combination of fever, dysphagia and pharyngeal congestion lead to a provisional diagnosis of retropharyngeal abscess, and an X-ray of the soft tissue neck was asked for. Surprisingly, X-ray (Fig. 2) showed a toe ring in the hypopharynx. It was confirmed and retrieved by esophagoscopy. He was discharged after parental counseling and registering in the local deaf and dumb society.

\section{Figure 2}

Figure 2: X-ray of neck showing the foreign body (toe ring) A. Anteroposterior and B. Lateral view

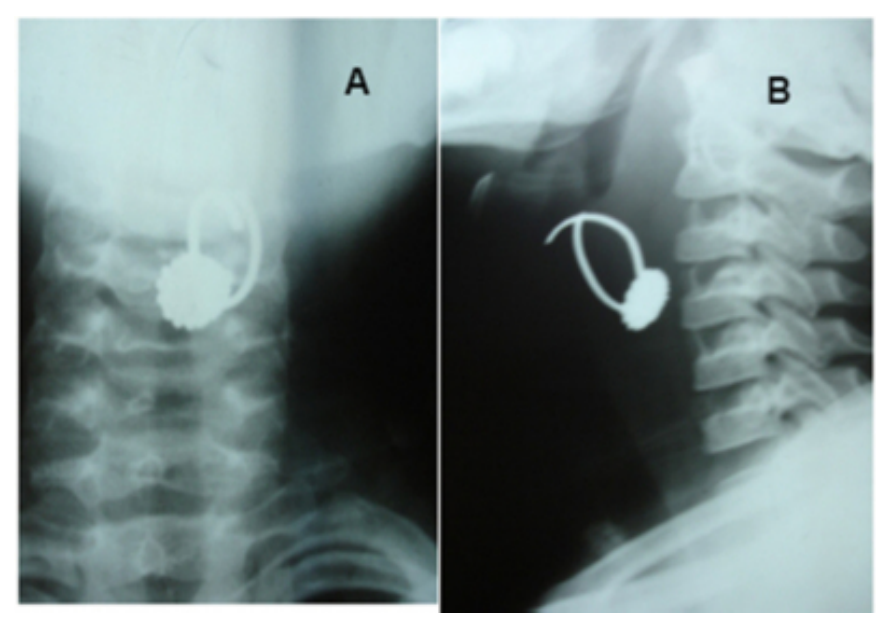

\section{DISCUSSION}

The incidence of swallowed foreign body in children is very high. The common age of occurrence is below 10 years. The most commonly ingested foreign bodies are coins followed by a variety of other objects like toy parts, batteries, a piece of bone, and food $\left.{ }_{2}\right]$. The common presenting symptoms are drooling of saliva, dysphagia and odynophagia. The anatomic proximity of the upper airway and esophagus even permit the development of respiratory symptoms like cough and stridor. A child with weight loss, consolidated lungs and failure to thrive are documented presentations of a long standing impacted foreign body in the esophagus $\left.{ }_{3}\right]$.

Presentation with aspiration pneumonia, mediastinitis and respiratory distress syndrome with a fatal outcome in a case of esophago-bronchial fistula caused by a plastic toy in the esophagus in a mentally retarded child has been reported $\left.{ }_{4}\right]$. A silent and asymptomatic foreign body in the esophagus of a child present for longer than 2 years has also been reported [5].

The problem encountered in diagnosis in our patient was his mental retardation and deaf and dumb status. Moreover, he had feeding difficulty and drooling of saliva since infancy. In the absence of any definite history of ingestion of a foreign body, these symptoms were not given much attention to by the parents and the physicians alike. Fever, cough and pharyngeal congestion are features of viral pharyngotosillitis, acute epiglottitis and retropharyngeal abscess. These diagnoses are entertained commonly in a child with dysphagia and fever. It is tempting to think of diphtheria too in the absence of immunization. It was fortunate that the foreign body was radio opaque and was readily picked up in the X-ray, leading to its prompt removal. In the background of low socioeconomic status, a deaf and dumb child who is also mentally retarded is mostly neglected, and not well cared for because he comes to no use to the family, especially in terms of child labor. In the absence of any history of foreign body ingestion in a compromised child, it is very difficult to attribute the cause of dysphagia initially to a foreign body. Since many patients who have swallowed foreign bodies are asymptomatic, only a high index of suspicion can point to its diagnosis. We highlight this as a rare cause of dysphagia in a mentally compromised, deaf and dumb child, and stress the fact that a probable foreign body should be kept in mind as its etiology to prevent undue morbidity.

\section{CORRESPONDENCE TO}

Dr. Sriparna Basu Department of Pediatrics Institute of Medical Sciences Banaras Hindu University Varanasi - 221 005 India Ph: 0091-9935340260 E-mail: drsriparnabasu@rediffmail.com

\section{References}

1. Kay M, Wyllie R. Pediatric foreign bodies and their management. Curr Gastroenterol Rep 2005 Jun;7(3):212-8.

2 . Uyemura MC. Foreign body ingestion in children. Am Fam Physician 2005 Jul 15;72(2):287-91.

3. Okoye IJ, Imo AO, Okwulehie V. Radiologic management of impacted coin in the oesophagus--a case 
report. Niger J Clin Pract 2005 Jun;8(1):56-9.

4. Schulz M, Wild L, Konig C, Kiess W, Siekmeyer W. An esophagobronchial fistula caused by an unusual foreign body in the esophagus leading to mediastinitis with fatal outcome.
Klin Padiatr 2006 Mar-Apr;218(2):85-7.

5. Jordan J, Sova J. Unusual case of the long term presence of esophageal foreign body (non-radiopaque coin) in children. Otolaryngol Pol 2005;59(2):281-3. 


\section{Author Information}

Sriparna Basu, M.D.

Department of Pediatrics, North Bengal Medical College and Hospital

Pranab Kumar Chandra, M.D.

Department of Pediatrics, North Bengal Medical College and Hospital

Somprakas Basu, M.S.

Department of Surgery, North Bengal Medical College and Hospital 